\title{
A Framework and Implementation of User Inter- face and Human-Computer Interaction Instruction
}

\author{
Alan Peslak \\ Penn State University, Dunmore, PA, USA
}

arp14@psu.edu

\section{Executive Summary}

Researchers have suggested that up to $50 \%$ of the effort in development of information systems is devoted to user interface development (Douglas, Tremaine, Leventhal, Wills, \& Manaris, 2002; Myers \& Rosson, 1992). Yet little study has been performed on the inclusion of important interface and human-computer interaction topics into a current information technology related curriculum. Particularly the IS (Information Systems) discipline has shown little interest in identifying and clarifying those topics and techniques that should be included in its curriculum. This paper reviews the literature in all areas of computing and information systems and sciences to determine importance of human-computer interaction and define interface topics that are generally regarded as most important for technology students. A review of classic, pedagogical and current HCI (human-computer interaction) literature is performed in this work. Within the broad category of HCI two major subcategories emerge - People and Process. Within these subcategories, twelve specific topic areas are identified. The topics are Interface Requirements, Interface and GUI (Graphical User Interface) Design, Interface Analysis, Assessment and Evaluation, Design Psychology, Human Behavior and Abilities, Implementation, Collaboration, Communications, and Teamwork, Costs/Benefits, Testing, Prototyping, and Disability. Each of these areas is vitally important to the future system designer. This study next reviews specific hands-on assignments to explore the topics identified. The computer science curriculum as proposed by the "Joint IEEE Computer Society/ACM Task Force" includes many of these important areas. The Information Systems Model curriculum only makes passing reference to HCI and Interface Design. The author currently teaches a junior level course in Organization and Design of Information Systems: User and System Principles. For the most part, this is a course in interface design and humancomputer interaction. The author has incorporated the twelve key concepts in both lecture materials as well as specific hands-on activities. The activities include HCI Gone Wild which challenges the students to prepare a fanciful, out-of-the-box interface to a common product or application. Sound exercise considers new uses and inclusion of an underutilized human sense. Expert elicitation explores the challenges of requirements analysis. User interface forces students to develop prototypes with disability issues in mind. Evaluation requires development of high level

Material published as part of this journal, either on-line or in print, is copyrighted by the publisher of the Journal of Information Technology Education. Permission to make digital or paper copy of part or all of these works for personal or classroom use is granted without fee provided that the copies are not made or distributed for profit or commercial advantage AND that copies 1) bear this notice in full and 2) give the full citation on the first page. It is permissible to abstract these works so long as credit is given. To copy in all other cases or to republish or to post on a server or to redistribute to lists requires specific permission and payment of a fee. Contact Editor@JITE.org to request redistribution permission. assessment, testing and communication skills so essential in interface design. The positive student evaluations of both the exercises and the course suggest that the materials and assignments are stimulating high interest and appreciation for the complexities of designing with the user in mind. Further course improvements that will be incorporated as a result of multiple semester feedback include 
more focus on subtleties of new technologies such as wireless, portals, and web services as well as inclusion of game design to even more actively engage students.

Keywords: Human-computer interaction, interface design, systems design, disability, prototyping, GUI design, design psychology, human behavior.

\section{Introduction}

The user interface has been recognized as one of the most important elements of a software project. It had been estimated that $48 \%$ of work on a project goes into the design and implementation of the user interface (Myers \& Rosson, 1992). Recently, as confirmation, Douglas, Tremaine, Leventhal, Wills, and Manaris (2002) noted the importance of Human Computer Interaction (HCI) suggesting at least $50 \%$ of programming code is devoted to the user interface. But the importance of interface design and the topics of human-computer interaction have not risen to a high level in information systems and sciences education. The importance of HCI has long gone unrecognized.

The purpose of this research paper is to develop "A Framework and Implementation of User Interface and Human-Computer Interaction Instruction". The goal is to explore the major issues that make up the diverse discipline that currently is most commonly known as human-computer interaction. Through a comprehensive review of classic, current, and pedagogical literature the essential topics that should be included in a survey course in HCI is then determined. Specific assignments that address each key area are next developed and tested. Finally, a brief review of the successes, limitations, and lessons learned from implementation of these exercises is explored. With such a large portion of systems work spent on designing the user interface for a systems project, the need for this study and its importance overall in information technology education is clear.

ACM SIGCHI defines HCI as follows: "Human-computer interaction is a discipline concerned with the design, evaluation and implementation of interactive computing systems for human use and with the study of major phenomena surrounding them." (Hewett, et. al, 2004). The definition suggests that HCI includes both People as well as Process issues. The first portion of this report is a review of the literature on the human-computer interaction in computing and information sciences curriculum. Paradoxically, most of the work that has been done on the incorporation of HCI into the curriculum has come through the computing sciences as opposed to the information sciences, though the information sciences are often viewed as more user and application oriented. There is little mention of human-computer interaction in the IS 2002 Model Curriculum and Guidelines for Undergraduate Degree Programs in Information Systems. The only mention is human-computer interface as a topic in IS 2002.3 - Information Systems Theory and Practice (Gorgone, et al., 2002). The second section of this report presents an implementation of HCI into an information technology (IT) curriculum with particular emphasis on process issues of design, requirements analysis, prototyping, and evaluation and people issues of human behavior and abilities, design psychology, and collaboration. The topics which have been recognized as critical for successful HCI design is followed by practical and tested exercises for classroom adoption which incorporate these concepts. Finally, evaluations of these exercises from two sections of the author's HCI class are reviewed, providing student support for the impact of these exercises.

\section{Research Methodology}

The research methods used in this pedagogical study included the following:

- Comprehensive review of HCI and IS and IT pedagogical research

- Review of Current pure HCI research 
- From the literature, a distillation of major topics that needed to be included in an undergraduate $\mathrm{HCI}$ course

- Specific exercises developed to address the identified major HCI topic areas

- Actual implementation of these exercises with junior undergraduate students

- Assessment of the results of these exercises through student survey and teacher assessment of quality of the projects.

- Discussion of findings and limitations of the study

The students who participated in the exercises and course content were part of a junior level course in the Information Sciences and Technology curriculum at our University named "Organization and Design of Information Systems: User and System Principles". This course has as its official course description, "Interdisciplinary survey of topics related to the use and usability of information systems." In practical terms, this course has served as a comprehensive survey of users, user interfaces including design, and human-computer interaction. The author has taught multiple sections of this IST course over several years and has evolved the course to include all the major topics that have been distilled in the literature review.

\section{Major Topics in the Research Literature}

As noted, information systems and sciences in general have primarily been silent on user interface design and the importance of human-computer interaction. But the computing sciences have discussed human-computer interaction for a number of years. Winograd (1990) in Proceedings of the SIGCHI Conference on Human Factors in Computing Systems, presented some of the major topics that needed to be covered in the (at that time) NEW domain of human-computer interaction. These included interface, work structure, supporting technologies, social processes, design processes, and assessment techniques. At the time, he offered a challenge to include in computer science curricula a course in human-computer interaction to "shift the center" of computer science and to understand and design systems for real users. Through "guided learning" he suggests students need to develop competency in understanding and devising user friendly systems and solutions.

Myers and Rosson (1992) confirmed the importance of interface design in a study performed in 1992. They surveyed a wide group of practitioners and found that nearly one-half (48\%) of all programming time is spent on the user interface. The percentage varied based on the phase of the life cycle with $45 \%$ of time in the design phase, $50 \%$ during implementation, and $37 \%$ during maintenance. Clearly an activity so important in software design needs to have significant coverage in information systems and sciences programs. McCauley (2003) presents summaries of studies that stress the importance of human-computer interaction. She notes that HCI is the seventh most important topic of twenty-five for software engineers and second on a list where software professionals did not know the topic sufficiently. Noted was the struggle to get HCI into the "Curricula 2001" because of the isolation of the HCI researchers from other mainstream computer research areas. She also notes little resources in ACM for HCI education.

Throughout the literature two broad areas have emerged from the development of a HumanComputer Interaction discipline - Processes and People. Within these overall areas, specific content categories emerge as well.

\section{Processes in $\mathrm{HCl}$}

A significant amount of research has been performed that focuses on the specific processes that are important for Human-Computer Interaction. Seffah (2003) reviews human-centered design (HCD) for software engineering activities. Nineteen specific skills were identified as being im- 
portant HCD skills from a review of the educational communities. There are two broad categories - prerequisite skills and specific skills. The prerequisite skills include general software and interface development methodologies. The specific skills include a broad range of topics which can be summarized under three broad categories - lifecycle, design, and evaluation. Lifecycle skills include integration of overall approach, user interface (UI), prototyping, and requirements analysis. Design issues incorporate modeling, screen layout, GUI design, web design, mobile design, and patterns and guidelines. Evaluation concepts take in testing, review, and documentation. The author presents a sample user interface design pattern including name, intent, focus, solution, applicability, and resulting context. Also presented is a modified spiral life cycle approach called DIRR of Design, Implement, Redesign, and Re-implement.

Recognizing the importance of HCI, Greenberg (1996) in ACM Interactions suggests that the teaching of human-computer interaction involves "examining design, implementation, and evaluation as a continual, integrated, and iterative process". In other words, there is a continuous cycle consisting of designing to specifications, some type of implementation of the design, either prototype or full, and then an evaluative process that examines if requirements have been satisfied. The result of the evaluation will result in a redesign and start of the process again. Greenberg notes the importance of:

- Design principles

- User evaluation both quantitative and qualitative

- Task-centered design

- Screen design

- Implementation

- Future visions

Some of the other research that discusses HCI in the curriculum includes the following authors. Strong (1995) noted HCI as a "fundamental, core topic". He suggests that HCI professionals come from a diverse background due to the diverse disciplines that $\mathrm{HCI}$ encompasses. He lists 52 different tasks that HCI practitioners perform including from requirements, thru design, analysis, and test and evaluation. Liffick and Yohe (2001) suggest that client/server monitoring and surveillance software can be utilized to perform HCI studies. This type of software may be useful in performing limited HCI study for educators or researchers. Rosson, Carroll, and Rodi (2004) suggest a scenario-based approach to HCI and usability instruction. The authors use a project to instruct requirements, analysis, design, prototyping, and evaluation. The use of case studies is seen as the best way to provide design and evaluation experience. The authors suggest that HCI is best learned by example. McCarthy and Aronson (2001) note the importance of design of websites for e-commerce success. Scheffelmaier and Vinsonhaler (2003) found the most frequent mention in a synthesis of existing web design research was "coherence" or "how well the site is structured and organized."

Finally, McCrickard, Chewar, and Somerveil (2004) discuss whether HCI should be classified as a science, an art, or an engineering discipline. The authors suggest that ultimately instruction must take place with HCI as an interdisciplinary combination of all three. There are significant elements of art including the essentials of design. Instruction can take place via case studies and include topics such as metaphors, affordance, and aesthetics. The science aspects include problem-based learning and techniques such as lab experiments, cognitive walkthroughs and Fitt's law. Engineering is instilled through decision-making cases and involves reengineering, storyboarding, and claims analysis.

Requirements analysis is at the forefront of pure HCI research including Duggan (2003, p. 373) who found "ineffective systems requirements determination (SRD) ... (as a) ... major problem in 
information systems delivery". Poor systems requirements have been the result of ineffective communications. Design environments are currently being extensively researched including "activity-oriented design environments" which include alternate prototype capabilities and innovative approaches to user modeling, design, and testing. (Akoumianakis \& Stephanidis, 2005)

\section{People in $\mathrm{HCl}$}

Other significant research has been done that focuses primarily on the impact of people and human characteristics in HCI. Lotze (2002) in the Proceedings of CHI suggests that in practice there is still little attention yet paid to human factors. Research is being conducted in a number of areas including limits of human processing, disabled user paradigms, natural HCI methods, improving HCI quality as well as reducing interface design costs. All of these are prime areas for research and hands-on educational activities. Myers, Hollan, and Cruz (1996, p. 794) define HCI as "the study of how people design, implement, and use interactive computer systems and how computers affect individuals, organizations, and society." Lazar, Preece, Gasen, and Winograd (2002) note that students tend not to focus on user interaction issues because they are too busy and too focused trying to keep up with rapidly changing technology. In addition, they use their own experience and ease of use as a bellwether on the usability of a system. This is often an inaccurate reading. HCI researchers and educators, however, do need to keep in mind HCI issues related to rapidly changing technology such as wireless, new design approaches such as distributed communities, user involvement, and a balance between theory and practice.

Many researchers have noted the importance of proper user design. Lundgren (1998) in his study of end-user support suggests that there is a greater need for support because systems are not designed properly in the first place. Ching, Glorfeld, and Hendrickson (1997) studied information systems and found that initial impressions of systems are "vital" to successful future use. Liebowitz (1998) suggests in designing multimedia systems that substance and style are both critical to systems success. The study of human behavior is important as machines take over roles and functions that have normally been the exclusive purview of humans. As robots and automated devices assume these duties it is important to model and understand the underlying human behavior and attributes of the behavior so they can be mimicked in robots (Thrun, 2004). Englefield and Tibbets $(2004$, p. 1) reviewed the HCI training that takes place at industry giant IBM, detailing the extensive program to "support the design of usable hardware and software products and the delivery of services and consultancy to commercial clients". This suggests "ongoing education is perceived as critical both to engage other stakeholders in the design process and to promote evolving best practice to HCI specialists. Training supports strategies for culture change at both an individual and organisational level."

Lazar (2003) notes that HCI accessibility is not a normal part of their HCI core curriculum, however the large disabled population requires designing web accessibility. He included a service learning project that included web design for disabled users. Recently, Lee, Katerattanakul, and Hong (2005) studied effectiveness of electronic commerce sites and found nine emergent factors associated with success including many that are directly the result of effect HCI design: helpful features, ease of transaction completion, reliability and flexibility, and security and trustworthiness. Greenberg (1996) in his seminal work also notes the importance of people in HCI including the importance of design psychology and human behavior.

People issues in HCI are a major component of pure HCI research. As an example, human awareness of its visual environment is extremely limited compared to its physical capabilities. This leads to a concept of "inattentional blindness". This attention limitation needs to be compensated for in systems and web design. (Varakin, Levin, \& Fidler, 2004). Sears, Feng, Oseitutu, and Karat (2003) current research focuses on sound and speech recognition related to interface design. Specifically, they are investigating difficulties in designing voice activated hands-free design. The 
importance of designing and implementing to avoid user frustration is emphasized by Ceaparu Lazar, Bessiere, Robinson, and Shneiderman (2004). They found that lost time associated with frustrating computer experiences wasted overall about $50 \%$ of a person's time spent on a computer and still was $38 \%$ after extreme cases were excluded. The importance of proper analysis, design, and assessment as well as a better understanding of human behavior are crucial for interface success. The importance of human characteristics and human behavior and cognitive styles are noted by Chen and Macredie (2004) who found important cognitive differences among study participants that suggest different model components to support web based instruction. Different cognitive styles require different approaches to reach these diverse students.

Reimer and Douglas (2004) studied various aspects of human behavior and design psychology through an exploration of information assimilation (IA). The study participants were found to not have adequate software to support gathering or information while surfing the web. Their IA from these activities can be supported by a proposed web-based E-notebook. Methods of evaluation

have come under review in recent times. A common method of heuristic evaluation was found to not provide the level of detail or complexity of problems that a new MOT (Metaphors of Thinking) approach provides. In MOT, certain human information processing metaphors (such as "Thinking as a stream of thought) are proposed and an interface is evaluated relative to this metaphor. (Hornbaek \& Frokjaer, 2004).

\section{Processes and People in $\mathrm{HCl}$}

Finally, comprehensive research has been performed that includes both process and people related HCI issues. Chan, Wolfe, and Fang (2002) studied 141 Masters MIS programs and found only "a few" with specific Human-Computer Interaction courses. The authors however studied three curriculum models - Model Curriculum and Guidelines for Graduate Degree Programs in Information Systems (ACM and AIS), Information Systems-Centric Curriculum, and the ACM SIGCHI Curricula for Human-Computer Interaction and found four major HCI topics covered in these guides:

- Interface design and cost/benefits of UCD (user centered design)

- HCI methods including testing and prototyping

- Design guidelines

- Web-based usability

There is a clear mix of both people issues such as usability and process issues such as testing and prototyping.

The pedagogical techniques suggested include both process and people related techniques

- Evaluation early

- HCI courses early

- Tangible deliverable development

- Team assignments

- Graphic design methods

- Real world clients

- Disability design

- Globalization design

- Wireless design 
One of the fourteen areas included in the Steelman draft of the "Computing Curricula 2001 Overview of the CS Body of Knowledge" is Human-Computer Interaction (The Joint Task Force on Computing Curricula, 2001). The core concepts that are considered "essential" include both people and process issues:

- Foundations - human diversity and capabilities, usability testing, web tools, design guidelines, and human performance issues

- Interface building- GUI toolkits, principles, and design

The elective categories include:

- Human-centered software development

- Graphical user-interface design

- Graphical user interface programming

- Multimedia systems

- HCI collaboration and communication

Cockburn and Bell (1998) suggest nine topics to be included in the HCI portion of a Software Engineering (SE) course: the human, the computer, interaction, usability principles, user-centered and task centered design, rationalized design, formal evaluation, and windowing. The author suggests teaching HCI at both ends of a curriculum - an introduction at the start and a detailed practical application at the end. Rozanski and Schaller (2003) include HCI throughout their curriculum and include the following topics:

- Usability engineering lifecycle

- User psychology

- Requirements Analysis

- User Interface design and implementation

- Testing

A recent article in the International Journal of Human-Computer Interaction reviews research over the past ten years and details trends in usability research. Many of the people and process areas which have previously explored are included here and include requirements methodology, user requirements, design methods, evaluation, testing, product design, implementation, human characteristics, user models, disability issues, and documentation and help (Kurosu, et al., 2004).

Overall, most authors agree that user interface design and human-computer interaction are extremely important topics that have not received enough attention in information and computing sciences education. The computer science community has recognized this and has had an active dialog on the inclusion of HCI into their courses. A similar effort should be undertaken to include $\mathrm{HCI}$ in information systems and sciences courses.

As a result of this literature review, twelve topic areas emerge as relevant for inclusion in an HCI curriculum. These topics are listed in Table 1. Table 1 illustrates the major topic areas identified in the research with the corresponding literature citations. Though there is some crossover between topics and categories, a general classification of each topic into a category is also presented in Table 1. 


\begin{tabular}{|c|c|c|}
\hline Major topic & Literature support & Category \\
\hline Interface Requirements & $\begin{array}{l}\text { Winograd (1990), Greenberg (1996) } \\
\text { Duggan (2003), Rozanski \& Schaller (2003), } \\
\text { Kurosu et al. (2004) }\end{array}$ & Process \\
\hline Interface and GUI Design & $\begin{array}{l}\text { Winograd (1990), Greenberg (1996) } \\
\text { Chan, Wolfe, \& Fang (2002), Seffah (2003) } \\
\text { Strong (1995), Myers, Hollan \& Cruz (1996) } \\
\text { Cockburn \& Bell (1998) } \\
\text { Rosson, Carroll, \& Rodi (2004) } \\
\text { McCrickard, Chewar, \& Somervell (2004) } \\
\text { Rozanski \& Schaller (2003) } \\
\text { Scheffelmaier and Vinsonhaler (2003) } \\
\text { Kurosu et al. (2004) }\end{array}$ & Process \\
\hline Interface Analysis & $\begin{array}{l}\text { Rosson, Carroll, \& Rodi (2004) } \\
\text { McCrickard, Chewar, \& Somervell (2004) } \\
\text { Strong (1995), Lundgren (1998) } \\
\text { Liebowitz (1998), Kurosu et al. (2004) }\end{array}$ & Process \\
\hline Assessment and evaluation & $\begin{array}{l}\text { Winograd (1990), Greenberg (1996) } \\
\text { Strong (1995), Cockburn \& Bell (1998) } \\
\text { Rosson, Carroll, \& Rodi (2004) } \\
\text { Hornbaek \& Frokjaer (2004) } \\
\text { Kurosu et al. (2004) }\end{array}$ & Process \\
\hline Design psychology & $\begin{array}{l}\text { Rozanski \& Schaller (2003), Greenberg (1996) } \\
\text { Ching, Glorfeld, \& Hendrickson (1997) } \\
\text { Lee, Katerattanakul, and Hong (2005) } \\
\text { Ceaparu et al. (2004) }\end{array}$ & People \\
\hline Human Behavior and Abilities & $\begin{array}{l}\text { Greenberg (1996), Lotze (2002), Thrun (2004), } \\
\text { Varakin, Levin, \& Fidler (2004) } \\
\text { Sears, Feng, Oseitutu, \& Karat (2003) } \\
\text { Chen \& Macredie (2004) } \\
\text { Reimer and Douglas (2004) } \\
\text { Kurosu et al. (2004) }\end{array}$ & People \\
\hline Implementation & $\begin{array}{l}\text { Rozanski \& Schaller (2003) } \\
\text { Greenberg (1996) } \\
\text { Kurosu et al. (2004) }\end{array}$ & People \\
\hline $\begin{array}{l}\text { Collaboration, communications, } \\
\text { and teamwork }\end{array}$ & $\begin{array}{l}\text { Winograd (1990) } \\
\text { Gorgone, et al. (2002) } \\
\text { Lazar, Preece, Gasen, \& Winograd (2002) } \\
\text { Chan, Wolfe, \& Fang (2002) }\end{array}$ & People \\
\hline Cost/Benefit & Lotze (2002), Chan, Wolfe, \& Fang (2002) & Process \\
\hline Testing & $\begin{array}{l}\text { Chan, Wolfe, \& Fang (2002), Seffah (2003) } \\
\text { Strong (1995), Rozanski \& Schaller (2003) } \\
\text { Akoumianakis \& Stephanidis (2005) } \\
\text { Kurosu et al. (2004) }\end{array}$ & Process \\
\hline Prototyping & $\begin{array}{l}\text { Chan, Wolfe, \& Fang (2002), Seffah (2003) } \\
\text { Akoumianakis \& Stephanidis (2005) }\end{array}$ & Process \\
\hline Disability & $\begin{array}{l}\text { Lazar (2003), Chan, Wolfe, \& Fang (2002) } \\
\text { Lotze (2002), Kurosu et al. (2004) }\end{array}$ & People \\
\hline
\end{tabular}


As illustrated the twelve topic areas that have received multiple supports in the literature.

\section{Assignments}

In addition, the author has developed custom exercises to allow hands-on implementation and application of the theoretical principles. In Table 2, the author has mapped the topic areas to specific exercises and course content in his IST course.

\begin{tabular}{|l|l|}
\hline \multicolumn{2}{|c|}{ Table 2. Major User Interface and HCI Topic and IST Assignments } \\
\hline Major topic & Assignments and other coverage \\
\hline Interface Requirements & Expert elicitation \\
\hline Interface and GUI Design & $\begin{array}{l}\text { HCI Gone Wild } \\
\text { User Interface } \\
\text { Sound exercise }\end{array}$ \\
\hline Interface Analysis & Bad Designs \\
& HCI Gone Wild \\
\hline Assessment and evaluation & Evaluation \\
& Journal \\
\hline Design psychology & Bad Designs \\
& HCI Gone Wild \\
& Text exercises \\
\hline Human Behavior and Abilities & Sound exercise \\
& HCI Gone Wild \\
& Bad Designs \\
& Journal \\
Expert Elicitation \\
\hline Implementation & User Interface \\
\hline Collaboration, communications, and team- & Team projects: \\
work & User Interface \\
& Evaluation \\
\hline Cost/Benefits & Evaluation \\
\hline Testing & Evaluation \\
\hline Prototyping & User Interface \\
\hline Disability & Sound exercise \\
& User Interface \\
\hline
\end{tabular}

Each of the assignments will now be detailed with limited examples of the work as well as the results of post-exercise surveys that evaluate the overall student rating of the application. Both the content and collaborative and non-collaborative tasks in my HCI course covered these topic areas. There were also GOMS (Goals, Operators, Methods, and Selections) and HTA (Hierarchical Task Analysis) assignments that were not recorded in surveys or documents.

\section{Bad Designs}

One of the first exercises that students are exposed to is the Bad Design exercise. The purpose of the exercise is to begin to understand some of the issues involved in interface design, incorporating design psychology and human behavior. The exercise has simple instructions:

Please review an assigned bad design and prepare to discuss. Please write a one paragraph review of problem and your unique solution. 
The students are assigned a specific example in the collection at the following URL: http://www.baddesigns.com

Generally this exercise was rated very highly. The applications on the website are not specifically information systems interfaces but rather poorly designed products. An example is the mop sink which is in a men's room and often mistaken for a urinal. Some sort of designation would be helpful to eliminate the confusion. The overall rating was a 4.1 (out of a possible 5.0, with 1=very poor, $2=$ poor, $3=$ average, $4=$ good and $5=$ very good). There were 32 respondents. This level of response was similar for other exercises and represents about $80 \%$ of the class. The Likert five response scale was the same for each exercise. The number of respondents varies somewhat by question due to attendance and survey completion, since it was not mandatory. The students gained a significant appreciation for bad design and human factors and we were able to generate a lively and humorous discussion of how not to design.

The topic areas covered most by this exercise were many including Interface and GUI design, Interface Analysis, Design Psychology, and Human Behavior.

\section{Sound Exercise}

Based on an exercise in the Dix, Finlay, Abowd, and Beale (2003) text, the sound exercise was an attempt to have students explore one of the less used senses in user interface and HCI design, hearing. The exercise was a paired team exercise and required the following.

Find programs or websites that could make use of sound better, see page 24-25 in text (worked exercise) for examples of use of sound. Propose and describe at least four uses of specific sounds in a one paragraph entry.

Some students struggled with this assignment, not initially appreciating the multiple and varied possibilities on the use of sound in user interface design. Two interesting examples of the possible uses of sound included adding sound to MapQuest and adding sound to websites for young children. The suggestion for MapQuest was to allow an audio download of directions spoken in your language that you record and put in a cassette player or CD in your car as you were driving to your destination. The audio directions would eliminate trying to drive and look at the directions at the same time. For web directions or young children's websites for children too young to read, the addition of sound directions for navigating through the website could be extremely helpful.

As a final comment the students expressed an understanding of how an alternative sense can be exploited to aid in usability of an interface or even as a sales tool. Overall rating for the exercise reflected some of the difficulties but remained above average. The mean was 3.6 (4.0 good).

The topic areas covered by this exercise were many including Interface and GUI design, Interface and GUI Design, Disability, and Human Behavior.

\section{Expert Elicitation Exercise}

This exercise is a variation of an exercise presented in the Noyes and Baber (1999) book. The key concept is to develop skills in interviewing and determining user requirements. The instructions are as follows:

Please pair with another student. One of your pair should assume the role of an expert in a task. The task can be any number of possibilities including creating a Java program, changing the oil in a car, or baking a cake, as long as that person understands all the steps in the task. The other person in the pair is the interviewer. That person needs to question the expert and record all the steps necessary to perform the task. 
The results for this exercise were mixed. Some students did not fully understand what was expected. Some just conducted a general interview with a person and did not focus on an expert task. Those who did understand and work through the exercise however found it invaluable. One pair provided a good review of how to perform a specific type of welding. Others focused on how to shoot basketball free throws. The overall survey results averaged a 3.7, well above average of 3.0.

The topic areas covered by this exercise were Interface Requirements and Human Behavior and Abilities.

\section{HCl Gone Wild}

The first and perhaps the most unique major assignment for the HCI students was something I called "HCI Gone Wild". The idea was to come up with a unique and creative interface. The concept did not have to be practical or able to be implemented. The goal was to encourage imagination and ideas. Wild and somewhat impractical concepts were encouraged. The specific instructions are noted.

Pick a product or application and develop a conceptual model of a new and unique interface to the product. The interface does not need to be practical in terms of actual implementation. Prepare a presentation and report on this HCI concept. This is an individual project.

This assignment rated very high within the major assignments with an average 4.1. There were many extremely interesting examples for this exercise. Many of the concepts displayed high creativity in both conception and design. Some of the more unusual items included:

- Pay by thumb - a thumb fingerprint method for payment at a vending machine. Your thumbprint would be matched be verified and then the amount of the purchase would be debited from your pre-paid account, similar to a turnpike toll E-Z pass.

- The Connected person - health monitoring clothing, headset displays, GPS, and other features all in attire for sensory enhancement.

- Smart car - traffic monitoring cruise control, headlights that anticipate where cars are going to move to next, automatic windshield wipers, automatic tinting windows, and automatic windshield wipers and washers.

The topic areas covered by this exercise were many including Interface and GUI design, Interface Analysis, Design Psychology, and Human Behavior and Abilities.

\section{User Interface}

To actually incorporate many of the concepts of HCI as well as focus on design, an actual user interface was required to be developed. The requirements were:

Develop a user interface for a electronic commerce company that targets a specific subsegment of the population such as:

- Elderly,

- Children,

- Visually handicapped,

- Young adult. 
Please prepare requirements specification and develop a prototype of the interface either drawn or using an electronic tool. A written report and oral presentation are required deliverables. This is a team project.

Many students had difficulty with this assignment and did not identify and target a specific market sub-segment. Average rating was 3.6, with more than 50\% rating the exercise as above average. Once again, those that did identify and target a sub-segment found significant value in the assignment. Future instructions will emphasize this important concept. Some interesting examples of target market included a web based grocery store for the elderly and home bound and a customizable web development suite for web programmers.

The topic areas covered by this exercise were many including Interface and GUI design, Implementation, Prototyping, and Disability.

\section{Evaluation}

One of the areas that receives almost no attention in any traditional information systems or sciences is evaluation. This is the focus of a major chapter in the Dix text and received about 4 weeks of classroom time in the course. The major project was to prepare and test an evaluation instrument. The instructions follow.

Prepare an evaluation instrument for an existing IT application. Have at least 3 users test the application and record their actions with the tool. Summarize the results and prepare conclusions. A written report and oral presentation are required deliverables. This is also a team project.

With this exercise being the last in the semester, and with other priorities and projects in other courses, the ratings for this exercise were above average at 3.6 but not as high as expected. However, the quality of the work prepared by the students as well as their experiences and presentations were exceptional. Most students developed surveys that measured common programs such as Access or MS Paint but some were more adventurous measuring AOL Instant Messenger and Visual Café, Webgain. Some students did open ended question interviews and one group did a focus group. The students were required to present their results and the variety and discussion that followed was an excellent way to describe the varied approaches to evaluation.

The topic areas covered by this exercise included Assessment and Evaluation, Costs, Collaboration, Communications, and Teamwork, and Testing.

\section{Journal}

The HCI Journal assignment was begun at the beginning of the semester and required students to make a weekly journal entry on HCI observances. The specific instructions specified:

You are required to keep a journal of HCI observances that you make during the term. The journal should have at a minimum, a weekly entry of an HCI interface and comments and suggestions about the interaction or interface. This is an individual project.

The pedagogical concept was to force students to examine interfaces and interaction issues in everyday life. Periodically students were asked to read portions of their journal to the class. The entries were often insightful and pertinent and though the students often complained, I believe the requirement did gradually open the eyes of students to the large number of HCI problems in everyday life. The hope is that recognition of the problems will foster a more concerted approach in formative user evaluation and more time spent on interface design and acceptability. As noted, the evaluation results were only marginally above average. Based on verbal feedback, perhaps the requirement of a weekly entry (15 in all) was excessive. The lessons could probably be learned in 
somewhat less but more detailed observations. This is how the assignment will be approached in future versions. The rating for this exercise was slightly above average at 3.1.

The topic areas covered by this exercise were generally Human Behavior and Assessment and Evaluation but may covered other areas as well.

\section{Topic}

A final project which crossed all twelve areas of the HCI and interface topics was the topic presentation. The students were to pick a topic from the list shown in Table 3 and follow these instructions:

Pick one of the following topics and prepare a minimum 5 slide PP presentation with the intention of a springboard for class discussion.

The topic was a mechanism to generate discussion on current issues in HCI. The results showed good popularity, earning a 3.8 rating.

\begin{tabular}{|l|}
\hline \multicolumn{1}{|c|}{ Table 3. Topics for presentation } \\
\hline Topics \\
\hline Impact of long term memory on website design \\
\hline Designing to overcome computer anxiety \\
\hline Cultural impact on Internet users \\
\hline HCI and privacy issues \\
\hline Virtual reality and computer interaction \\
\hline Designing to prevent mistakes \\
\hline Latest developments in biometric interfaces \\
\hline GUI versus command based interfaces \\
\hline Color and its impact on interfaces \\
\hline Use of style guides in web design \\
\hline Influence of video games on interface design \\
\hline Good versus bad icons \\
\hline The automated home \\
\hline Advantages and disadvantages of different keyboards \\
\hline Review of speech recognition technology \\
\hline Image compression technologies \\
\hline Error message design \\
\hline Review of video conferencing technologies \\
\hline HCI in medical applications \\
\hline HCI in criminal applications \\
\hline HCI in creation of computer animation \\
\hline
\end{tabular}

\section{Results}

Overall, the results of all the exercises were significantly above an average score of 3.0. The complete results are shown in Table 4. The highest rated exercises were those that involved the most creativity, namely Bad Designs and HCI Gone Wild. Both allowed students to creatively explore what makes up a good and a bad design. In the first exercise, the student explored humorous and unusual designs for a wide variety of products. Their surprise at the extent and number of bad designs opens their eyes to the problems of HCI. On the other hand, HCI Gone Wild allows them to absorb the lessons learned from Bad Designs and actually develop an interface that is creative and well designed and meets the needs of their user populations. Both exercises 
emphasize the importance of good design but from opposite perspectives. And quite frankly, both of these exercises are the most fun. HCI Gone Wild was actually the highest rated exercise and exhibited the least variation with a standard deviation of only .71. On the other end of the spectrum, the journal writing had the lowest score. Some students balk at the commitment of recording observations in everyday life of both good and bad design. The Journals also exhibited the most variation in scores with a standard deviation of 1.2.

As noted, though the importance remains, the frequency and number of entries will be reduced.

\begin{tabular}{|l|c|c|}
\hline \multicolumn{3}{|c|}{ Table 4. Assignment Results } \\
\hline $\begin{array}{c}\text { Assignments and } \\
\text { other coverage }\end{array}$ & $\begin{array}{c}\text { Average Rating } \\
\text { on scale 1-5 }\end{array}$ & Std. Deviation \\
\hline Expert elicitation & 3.70 & 1.03 \\
\hline HCI Gone Wild & 4.11 & .71 \\
\hline Evaluation & 3.56 & .99 \\
\hline Bad Designs & 4.09 & .96 \\
\hline Sound exercise & 3.64 & .78 \\
\hline User Interface & 3.64 & .87 \\
\hline Journals & 3.13 & 1.20 \\
\hline Topic & 3.84 & .73 \\
\hline
\end{tabular}

\section{Limitations}

Though a comprehensive review of the relevant literature was performed and specific exercises were developed to match the important topics, the field of HCI is continuously evolving. New topics are rising to importance every day. As a result, in a recent version of the course the author has included and emphasized the exploration of new current events that have relevance for IT professionals and students. One of the most important sources for these current events has been the ACM TechNews service. Though targeted to include all relevant current IT news, the service often devotes nearly $50 \%$ of its content to current developments in the field of Human-Computer Interaction. Another area that will be included in future versions of the course are the rising importance of web services and portals and the unique HCI challenges associated with these paradigms. In addition, an increased emphasis on designing wireless, handheld, and cell phones will be included.

\section{Discussion}

The study is an attempt to categorize important topics that deserve attention in undergraduate HCI courses. As noted there are a wide and diverse group of topics that need to be addressed to adequately prepare students for successful interface development.

In general, both students and educators have not given proper attention to one of the most important areas of systems and technology development, namely the importance of human and computer factors and the major challenges facing the interface between these two areas. Most IS programs as well as the 2002 model IS curriculum do not include this area in their programs. This is unfortunate and results in analysts and programmers who do not have adequate appreciation of the importance of HCI. Also, they sadly lack the skills and tools necessary to create truly effective systems, interfaces, or even documentation. As an exercise in a recent class, I had as an inclass assignment, the development of a Pivot Table in Microsoft Excel using only the help and support provided within Excel. Most students had never developed a pivot table but there is a brief tutorial and considerable help available from the software. Out of a class of twenty, only one student was able to accomplish the task. Unfortunately, these results suggest problems with three 
aspects of this particular feature, the help provided, the feature wizard, or the feature interface itself. All of these issues can be significantly improved by a better understanding and implementation of HCI issues as outlined in this research report.

Some of the recommendations I would propose for other educators would be first, a hands-on approach to implementing the HCI people and process topics. I would recommend explicit directions on the completion of the hands-on assignments. I would include ample in-class exercises, a good reference text such as Dix, and ample opportunity for students to interact and share their findings and insights with the class. In future classes, I would like to explore HCI and game theory as well as entertainment theory. In order to more actively engage student I would like to examine the crossover between video game theory and implementation and traditional interactive systems. A review of computing and entertainment can be effectively supported by a new ACM scholarly publication, Computers in Entertainment. In a longer version of the course, a complete project such as website or a video game would be developed from start to finish specifically addressing all of the people and process HCI issues.

\section{Conclusion}

In general the proposal is a comprehensive approach to incorporate the twelve areas of HCI and interface design as identified in the literature review into a practical course incorporating principles learned through hands-on exercises. The author notes that all exercises were rated by the students as above average. The assessment of the instructor was that the course was a success with grades and learning outcomes achieved. Some areas will be modified slightly in future versions of the course but the overall twelve principles and hands-on flavor will be retained. Clearly, HCI needs to be incorporated into information systems and sciences education. This approach provides a framework and examples to include this knowledge into the curriculum. The author invites comments and collaboration efforts to strengthen the pedagogical knowledge base for HCI in IT and IS.

\section{References}

Akoumianakis, D. \& Stephanidis, C. (2005). building consensus in human-computer interaction design: Integrated activity-oriented design environments. International Journal of Human-Computer Interaction, 18 (1), 85-103.

Ceaparu, I., Lazar, J., Bessiere, K., Robinson, J., \& Shneiderman, B. (2004). Determining causes and severity of end-user frustration. International Journal of Human-Computer Interaction, 17 (3), 333-356.

Chan, S., Wolfe, R., \& Fang, X. (2002). Teaching HCI in IS/EC curriculum. Eight Americas Conference on Information Systems, 1011-1020.

Chen, S. \& Macredie, R. (2004). Cognitive modeling of student learning in web-based instructional programs. International Journal of Human-Computer Interaction, 17 (3), 403-426.

Ching, R., Glorfeld, L., \& Hendrickson, A. (1997). Predictive change to perceived information system use. Journal of Computer Information Systems, 37 (2), 96-100.

Cockburn, A. \& Bell, T. (1998). Extending HCI in the computer science curriculum. Proceedings of the third Australasian conference on Computer science education, 113- 120.

Dix, A., Finlay, J., Abowd, G., \& Beale, R. (2003). Human-Computer Interaction (Third Edition). Harlow, England: Prentice Hall.

Douglas, S., Tremaine, M., Leventhal, L., Wills, C., \& Manaris, B. (2002). Incorporating human-computer interaction into the undergraduate computer science curriculum, Proceedings of the 33th SIGCSE technical symposium on Computer science education, 211-212. 
Duggan, E. (2003). Generating systems requirements with facilitated group techniques. Human-Computer Interaction, 18, 373-394.

Englefield, P. \& Tibbits, M. (2004). HCI training in industry: Business, pragmatism, and collaboration. 7th Workshop on Effective Training and Education in HCI, University of Central Lancashire, 1st April/2nd April 2004. Available at: http://www.ics.ltsn.ac.uk/pub/HCI2004/

Gorgone, J., Davis, G., Valacich, J., Heikki, T., Feinstein, D., \& Longenecker, Jr., H. (2002). IS 2002 Model Curriculum and Guidelines for Undergraduate Degree Programs in Information Systems, Available at: http://www.acm.org/education/is2002.pdf

Greenberg, S. (1996). Teaching human-computer interaction to programmers. Interactions, 3 (4), 62-76.

Hewett, T., Baecker, R., Card, S., Carey, T., Gasen, J., Mantei, M., Perlman, G., Strong, G., \& Verplank, W. (2004). ACM SIGCHI Curricula for Human-Computer Interaction, Available at: http://sigchi.org/cdg/cdg2.html

Hornbaek, K. \& Frokjaer, E. (2004). Usability inspection by metaphors of human thinking compared to heuristic evaluation. International Journal of Human-Computer Interaction, 17 (3), 357-374.

The Joint Task Force on Computing Curricula. (2001). Computing Curricula 2001 Computer Science Steelman Draft. (2001). Available at: http://www.computer.org/education/cc2001/steelman/cc2001/cc2001-steelman.pdf

Kurosu, M., Kobayashi, T., Yoshitake, R., Takahashi, H., Urokohara, H, \& Saro, D. (2004). Trends in usability research and activities in Japan. International Journal of Human-Computer Interaction, 17 (1), 403-426.

Lazar, J. (2003). Improving web accessibility through service-learning partnerships, Proceedings of ISECON 2003, v 20 (San Diego), ISSN: 1542-7382. (Also appears in Information Systems Education Journal 1: (33). ISSN: 1545-679X.)

Lazar, J., Preece, J., Gasen, J., \& Winograd, T. (2002). New issues in teaching HCI: Pinning a tail on a moving donkey. CHI '02 extended abstracts on Human factors in computing systems, 696-697.

Lee, S., Katerattanakul P., \& Hong, S. (2005). Framework for user perception of effective e-tail web sites. Journal of Electronic Commerce in Organizations, 3 (1), 13-34.

Liebowitz, J. (1998). Experiences with multimedia development: A personal look. Journal of Computer Information Systems, 38 (1), 15-19.

Liffick, B. W. \& Yohe L. K. (2001). Using surveillance software as an HCI tool. Proceedings of ISECON 2001, v 18 (Cincinnati), 2001.

Lotze, P. (2002). Directions in HCI education, research, and practice in Southern Africa. Proceedings of CHI 2002, 524-525.

Lundgren, T. (1998). End-user support. Journal of Computer Information Systems, 39 (1), 60-64.

McCarthy, R. \& Aronson, J. (2001). Activating consumer response: A model for web site design strategy. Journal of Computer Information Systems, 41 (2), 2-8.

McCauley, R. (2003). Resources for teaching and learning about human-computer interaction. Inroads-The SIGCSE Bulletin, 35 (2), 16-17.

McCrickard, D., Chewar C., \& Somervell J. (2004). Design, science, and engineering topics? Teaching HCI with a unified method. Proceedings of the 35th SIGCSE technical symposium on Computer science education, 31-35.

Myers, B., Hollan, J. \& Cruz, I. (1996). Strategic directions in human-computer interaction. ACM Computing Surveys (CSUR), 28 (4), 794-809.

Myers, B. \& Rosson M. (1992). Survey on user interface programming. Proceedings SIGCHI'92: Human Factors in Computing Systems, 195-202. 
Noyes, J. \& Baber, C. (1999). User-Centered Design of Systems. Heidelgerg, Germany: Springer Verlag.

Reimer, Y. \& Douglas, S. (2004). Ethnography, scenario-based observational usability study, and other reviews inform the design of a web-based e-notebook. International Journal of Human-Computer Interaction, 17 (3), 403-426.

Rosson, M., Caroll, J., \& Rodi, C. (2004). Case studies for teaching usability engineering. Proceedings of the 35th SIGCSE technical symposium on Computer science education, 36-40.

Rozanski, E. \& Schaller N. (2003). Integrating usability engineering into the computer science curriculum - A proposal. ACM SIGCSE Bulletin, Proceedings of the 8th Annual Conference on Innovation and Technology in Computer Science Education, 35 (3), 202-206.

Scheffelmaier, G. \& Vinsonhaler, J. (2003). A synthesis of research on the properties of effective internet commerce web sites. Journal of Computer Information Systems, 43 (2), 23-30.

Sears, A., Feng, J., \& Oseitutu, K. (2003). Hands-free, speech-based navigation during dictation: Difficulties, consequences, and solutions. Human-Computer Interaction, 18, 229-257.

Seffah, A. (2003). Learning the ropes: Human-centered design skills and patterns for software engineers' education. Interactions, 10 (5), 36-45.

Strong, G. (1995). New directions in human-computer interaction: education, research, and practice. Interactions, 2 (1), 69-81.

Thrun, S. (2004). Toward a framework for human-robot interaction, Human-Computer Interaction, 19, 924.

Varakin, D., Levin, D., and Fidler, R. (2004). Unseen and unaware: Implications of recent research on failures of visual awareness for human-computer interface design, Human-Computer Interaction, 19, 389422 .

Winograd, T. (1990). What can we teach about human-computer interaction? Proceedings of the SIGCHI conference on Human factors in computing systems: Empowering people, 443-449.

\section{Biography}

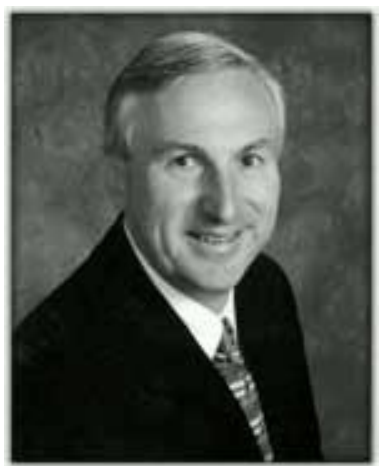

Alan R. Peslak is an Assistant Professor of Information Sciences and Technology at Penn State University, Worthington Scranton. He received his Ph.D. in Information Systems from Nova Southeastern University, Fort Lauderdale, Florida. He has over 25 years of industry experience. Dr. Peslak's research focuses on the economic, ethical and societal impacts of information technology. He has published in the Information Resources Management Journal, Journal of Computer Information Systems, Information Research, and First Monday. He is a member of ACM, AITP-EDSIG, IACIS, and ACM-SIGMIS. He can be reached at arp14@psu.edu and 570-963-2640. 